\title{
A study on occurrence of anemia in primigravida women attending antenatal ward of BPKIHS
}

\author{
U Yadav, B Lal das \\ College of Nursing \\ B. P. Koirala Institute of Health Sciences, Dharan, Nepal
}

\begin{abstract}
Background: Anemia is identified as a very common nutritional problem in developing countries. Prevalence of micro nutrient malnutrition in respect of iron, iodine and vitamin $A$ is more wide spread then protein energy malnutrition. Pregnancy is a serious burden to the women with the disease for the anemia and places them at increased risk of mortality. Objective: To determine the $\mathrm{Hb} \%$ level of Primigravida women. To classify status of anemia on the basis of level of $\mathrm{Hb} \%$. To find out the association between $\mathrm{Hb}$ level and selected background factors. To find out the association between the $\mathrm{Hb} \%$ level and week of gestation and nutritional pattern. Method: A descriptive and exploring Study design was carried out on 300 primigravid women admitted in BPKIHS, Dharan antenatal ward and every alternate admitted case was selected for the study. The instrument was structured questionnaires with close ended, observation check list and observational sheet. Descriptive statistics and inferential statistics were used for data analysis. Result: Overall occurrence of anemia was found to be $42 \%$ among the study population. Mild anemia and moderate anemia were found to be $17 \%$ and $25 \%$ respectively. Greater proportions of $13-19$ yr. women were found to be anemic compares to those $\geq 20$ years of age. Greater proportions of anemic women were from the nonsedentary groups than the sedentary. Both mild and moderate anemia were more among Primigravid women with >40 gestational week. Conclusion: Understanding the extent and severity of anemia among pregnant women is essential to the development and implementation of effective anemia control for the normal delivery and healthy baby in Nepal.
\end{abstract}

Key words: Anemia, lodine deficiency, primigravida women.

\footnotetext{
Address for correspondence

Upendra Yadav

College of Nursing,

B.P. Koirala Institute of Health Sciences, Dharan

Email: upendrayadav2010@yahoo.com
} 


\section{Introduction}

Iron deficiency anemia is the most common nutritional deficiency would wide affection approximately 1.3 billion people. Anemia is identified as a very common nutritional problem in developing countries. Prevalence of micro nutrient malnutrition in respect of iron, iodine and vitamin $A$ is more wide spread then protein energy malnutrition. Pregnancy is a serious burden to the women with the disease for the anemia and places them at increased risk of mortality. Moderate to severe anemia during pregnancy increase the risk of low birth weight.

\section{Methods}

This is a descriptive research study and the research approach was Survey Method. The study was done in a tertiary level of care BPKIHS Dharan. All primigravida women of $>$ 28 weeks of gestation admitted in antenatal ward were included in the study. Samples of the study were primigravida women admitted in BPKIHS, Dharan antenatal ward. The size of the sample was 300 .

The instrument was structured questionnaires with close ended, observation check list and observational sheet. The collected data were tabulated, organized, analyzed and interpreted using descriptive and inferential statistics.

\section{Results}

Table 1: Distribution of occupation by different grade of anaemia ( $N=300)$

\begin{tabular}{|l|l|l|l|}
\hline S.N. & \multicolumn{1}{|c|}{ Grade of anaemia (gm \%) } & \multicolumn{1}{|c|}{ Sedentary } & \multicolumn{1}{|c|}{ Non-sedentary } \\
\hline 1 & No anemia $(>10.9)$ & $65(21 \%)$ & $108(36 \%)$ \\
2 & Mild anaemia (10-10.9) & $32(10.7 \%)$ & $56(18.7 \%)$ \\
3 & Moderate anaemia (7-9.9) & $16(5.3 \%)$ & $20(6.7 \%)$ \\
4 & Severe anaemia (<7gm ) & $1(0.3 \%)$ & $2(0.7 \%)$ \\
\hline & Total & $114(38 \%)$ & $186(62 \%)$ \\
\hline
\end{tabular}

Table 2: Occurrence of anamia in relation to income $(\mathrm{N}=300)$

\begin{tabular}{|l|l|l|l|}
\hline S.N. & \multicolumn{1}{|c|}{ Grade of anaemia (gm \%) } & \multicolumn{1}{|c|}{$1000-3000$} & \multicolumn{1}{|c|}{$>3000$} \\
\hline 1 & No anemia (>10.9) & $83(27.66 \%)$ & $90(30 \%)$ \\
2 & Mild anaemia (10-10.9) & $55(18.33 \%)$ & $33(11 \%)$ \\
3 & Moderate anaemia (7-9.9) & $22(7.33 \%)$ & $14(4.66 \%)$ \\
4 & Severe anaemia (<7gm ) & $3(1 \%)$ & $0(0 \%)$ \\
\hline & Total & $163(54.33 \%)$ & $137(45.66 \%)$ \\
\hline
\end{tabular}


Table 3: Comparison of anamia by dietary pattern ( $\mathrm{N}=300)$

\begin{tabular}{|l|l|l|l|}
\hline S.N. & \multicolumn{1}{|c|}{ Grade of anaemia (gm \%) } & \multicolumn{1}{|c|}{ Vegetarian } & \multicolumn{1}{|c|}{ Non-vegetarian } \\
\hline 1 & No anemia $(>10.9)$ & $38(12.7 \%)$ & $70(23.3 \%)$ \\
2 & Mild anaemia (10-10.9) & $18(6 \%)$ & $31(10.3 \%)$ \\
3 & Moderate anaemia (7-9.9) & $5(1.7 \%)$ & $3(1 \%)$ \\
4 & Severe anaemia (<7gm ) & $0(0 \%)$ & $\mathbf{2 3 9 ( 7 9 . 7 \% )}$ \\
\hline & Total & $\mathbf{6 1 ( 2 0 . 3 \% )}$ & \\
\hline
\end{tabular}

Table 4: Distribution of size of family by grade of anaemia $(\mathrm{N}=300)$

\begin{tabular}{|l|l|l|l|l|}
\hline SN & \multicolumn{1}{|c|}{ Grade of anaemia (gm \%) } & \multicolumn{1}{|c|}{$1-3$} & \multicolumn{1}{|c|}{$>7$} \\
\hline 1 & No anemia (>10.9) & $18(6 \%)$ & $70(23.3 \%)$ & $85(28.3 \%)$ \\
2 & Mild anaemia (10-10.9) & $10(3.3 \%)$ & $42(14 \%)$ & $36(12 \%)$ \\
3 & Moderate anaemia (7-9.9) & $2(0.7 \%)$ & $18(6 \%)$ & $16(5.3 \%)$ \\
4 & Severe anaemia (<7gm ) & $0(0 \%)$ & $2(0.7 \%)$ & $1(0.3 \%)$ \\
\hline & Total & $30(10 \%)$ & $132(44 \%)$ & $138(46 \%)$ \\
\hline
\end{tabular}

Table 5: Occurrence of anamia in relation to gestational weeks $(\mathrm{N}=300)$

\begin{tabular}{|l|l|l|l|l|}
\hline SN & Grade of anaemia (gm \%) & \multicolumn{1}{|c|}{$28-36$ weeks } & \multicolumn{1}{|c|}{$36-40$ weeks } & \multicolumn{1}{|c|}{$>$ weeks } \\
\hline 1 & No anemia $(>10.9)$ & $19(6.3 \%)$ & $107(35.7 \%)$ & $47(15.7 \%)$ \\
2 & Mild anaemia $(10-10.9)$ & $7(2.3 \%)$ & $46(15.3 \%)$ & $35(11.7 \%)$ \\
3 & Moderate anaemia (7-9.9) & $3(1 \%)$ & $25(8.3 \%)$ & $36(12 \%)$ \\
4 & Severe anaemia $(<7 \mathrm{gm})$ & $1(0.3 \%)$ & $1(0.3 \%)$ & $3(1 \%)$ \\
\hline & Total & $30(10 \%)$ & $179(59.7 \%)$ & $91(30.3 \%)$ \\
\hline
\end{tabular}

\section{Conclusion}

Understanding the extent and severity of anemia among pregnant women is essential to the development and implementation of effective anemia control for the normal delivery and healthy baby in Nepal.

\section{Reference}

1. WHO, the World Health Report 2015, 75.
2. Heera Tuladhar. Anaemia in adolescent pregnancy. Nepal Medical College Journal, 2000;2: 19-21.

3. Michael L. Dreytun, Jay Bahadur Shrestha, Subarna Khatri, et al. The prevalence of anaemia among pregnant and lactating women and among their infants in Sarlahi District, 1997; 35: 234240. 
4. D. T. Howe Guernsey, The influence of material haemoglobin and ferritin or mid pregnancy placental volume. British journal of Obstetrics and Gynaecology. 1995: 213-219.

5. ICN, Information on anaemia prepared by member countries of South East Asia region (Bangladesh, Bhutan, India, Indonesia, Myanmar, Thailand). 1992: 81-82.

6. Seshdri, A. data base on Iron Deficiency Anaemia (IDA) in India: Prevalence, aetiology, consequences and strategies for control. 1996. Ministry of Human Resource Development, New Delhi.

7. ICMR, Task force study. Evaluation of National Nutritional Anaemia Prophylaxis Programme. Indian Council of Medical Research, New Delhi,1989: 101-103.

8. Agrawal DK, Agrawal $\mathrm{KN}$ and Tripathi AM. Nutritional status in rural pregnant women of Bihar and Uttar Pradesh. Indian J. Paediatrics, 24:119-125.

9. Premak, Neeta Kumar's and Ramalakshmi BA. Anaemia and adverse obstetric outcome Nutr. Rep. 23:637637-643.
10. Rahmanifar $A$ and Bond JT. Haemotological status of urban pregnant women from different socio - economic populations in central Iran Nutrition Research, 1989; 9:1313-1330.

11. Geisser C. Calloway DH and Mayers. Lactation and pregnancy in Iran: diet and Nutritional Status, 1987.

12. WHO. Control of Iron deficiency anaemia in South East Asia report of an inter country workshop. World Health Organization Regional Office for South East Asia, New Delhi, 1996 - b.

13. Chhetri $M$ Weise $L$ Joshi, N Shrestha $S$ and Tiwari K. Anaemia is pregnant women in Nepal: Strategies improve compliance with iron supplementation. Ministry of Health, Nepal and WHO, 1994.

14. Karim SA, Khursheed M, Rizyi JH Jafaray $\mathrm{SN}$ and Siddiqui RI. Anaemia in pregnancy: A study of fog women in Karachi. Tropical Doctor, 1990, 20:184185.

15. Mudalige R. and Nestel P. Combating iron-deficiency: Prevalence of anaemia in Srilanka. Ceylong J. Med. Sci, 1996; 39:9-16. 